\title{
A Psicologia Comunitária nas Américas: o Individualismo, o Comunitarismo e a Exclusão do Político
}

\author{
Marco Aurélio Máximo Prado ${ }^{1}$
}

Universidade São Marcos, São Paulo

\begin{abstract}
Resumo
Este texto apresenta um denominador comum entre a Psicologia Comunitária na América do Norte e na América Latina, entendido a partir do fim do espaço do político. Neste sentido, a partir da filosofia política, pretende-se uma análise crítica das duas posições (individualista e comunitarista) na Psicologia Comunitária, explicitando a importância do político no debate contemporâneo de uma Psicologia comprometida com a extensão dos valores democráticos. Palavras-chave: Psicologia comunitária; individualismo; comunitarismo; político.
\end{abstract}

Community Psychology in the Americas: Individualism, Communitarism and the Exclusion of the Political.

Abstract

This paper discusses the end of the political, seen as a common denominator between Community Psychology in North and Latin America. Based on political philosophy, this paper proposes a critical analysis of two positions in Community Psychology, individualism and communitarism, thereby emphasizing the importance of the political in contemporary debates of a psychology engaged in the extension of democratic values.

Keywords: Community psychology; individualism; communitarism; political.

\section{Introduzindo o Debate}

Não é novidade, especialmente para os psicólogos sociais da América Latina, a distância existente entre as Psicologias nos dois pólos da América. As Américas, separadas por tantos motivos, também se distanciam quando se pensa na Psicologia Social e, particularmente, nos fazeres que envolvem a Psicologia Comunitária (PC).

Neste texto, buscamos explorar um outro ponto de vista que não o da distância, mas sim o da proximidade entre a Psicologia Comunitária Latino-americana (Andery, 1984; Lane, 1995; Prado, 1994; Wiesenfeld, 1994) e Norte-americana² (Kelly, 1990; Linney, 1990; Novaco \& Manahan, 1980). Para tal, retomaremos as principais posições teóricas de cada uma (Montero, 1994), com o intuito de apontar um denominador comum entre a Psicologia Comunitária nas Américas, o qual estaria dado pela noção de fim do espaço do político e que, em nossa visão, é um dos debates críticos que poderia auxiliar na construção de uma Psicologia preocupada com a radicalização da democracia.

${ }^{1}$ Endereço para correspondência: Rua Irmão Gonçalo, 74 apto 52. Vila Madalena, São Paulo, SP, 05439-080. Fone: (11) 3031.3741. E-mail: aurelioprado@uol.com.br

2 Norte-americana refere-se a Psicologia Comunitária desenvolvida nos EUA, e Latino-americana diz respeito a Psicologia Comunitária e Social que se desenvolveu na maioria dos países da América Central e do Sul.
Nosso argumento se construirá através do pensamento desenvolvido pela filósofa Chantal Mouffe (1993; 1995; 1996; 1999), acerca do político e de suas críticas tanto ao pensamento liberal como comunitarista, a partir da tradição do pensamento político de Carl Schmitt ${ }^{3}$. Com Mouffe (1993), trataremos de identificar que a Psicologia Comunitária nas Américas, apesar de muitas diferenças e distâncias, estão próximas quando relativas ao pensamento político, ou seja, as duas concepções de Psicologia Comunitária acabam por propor, mesmo que inversamente, o fim do político.

Seja a Psicologia Comunitária Norte-americana (PCNA) em uma concepção mais liberal ou a Psicologia Comunitária Latino-americana (PCLA) em uma concepção mais comunitária, as duas correm o risco de se tornarem um legitimador antipolítico, já que, como veremos no desenvolvimento de nossos argumentos, nas duas posições, uma delas mais individualista e outra mais coletivista, o político reduz-se a um consenso, ora racional e instrumental, ora coletivista e redentor.

${ }^{3} \mathrm{O}$ autor foi o responsável pela noção do político balizado como a relação entre amigo/inimigo, de maneira que a Política se realizaria através do antagonismo da relação entre a associação de amigos que defendemse de ingos. Bo

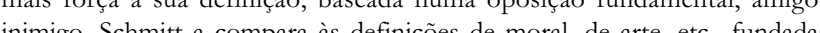

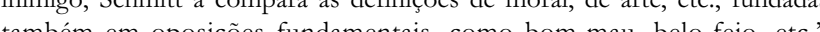
(p. 959). 
Num cenário de grandes mudanças mundiais (Heller 1999; Laclau, 1990; Santos, 1994; Touraine, 1995), discussão política tem sido uma das grandes vedetes do momento, ao contrário do que alguns intelectuais imaginaram, o político e a história não encontraram seu fim. As questões políticas passaram a fazer eco dentro de todos os grupos sociais, e não somente elas, mas também as reflexões éticas invadiram o nosso cotidiano, especialmente o cotidiano de uma civilização que alcançou o controle sobre o sistema global, sobre a natureza e sobre a reprodução humana.

Neste sentido, tanto a política como a ética ressuscitaram questões tão fundamentais para a humanidade como estas a que a Psicologia Comunitária nas Américas parece confrontar: é possível a vida em comunidade? como pensar a participação social dos indivíduos? a construção de uma comunidade política? como garantir o aprofundamento da igualdade sem ameaças às liberdades individuais? como combater o individualismo crescente? como aprofundar os valores democráticos?

Assim como a relação entre indivíduos e coletividade, o político também pode ser definido por diferentes abordagens. Se pensarmos, em apenas duas das mai importantes concepções sobre o político, podemo elencar a tradição liberal e a tradição comunitarista. Uma buscando defender a liberdade individual sobre a noção de legitimidade coletiva do bem comum e a outra respectivamente, apontando os perigos do acirramento individual em um individualismo excêntrico e a importância de uma definição de bem comum coletivo como parâmetro único para as posições individuais e para a vida institucional democrática.

Este tem sido um dos principais debates junto a Filosofia Política moderna (Heller, 1991; Mouffe, 1993) e ele está centrado, sobretudo, em comparar os dois sistemas políticos e filosóficos para uma melhor compreensão dos problemas mundiais atuais no ocidente.

Buscamos, de maneira bastante sintética, expor alguns dos principais argumentos sobre o político defendido por Mouffe (1999), os quais podem nos ajudar a alimenta o debate acerca das reflexões dilemáticas que se impõem, na contemporaneidade, a uma Psicologia que se pretende compromissada com o aprofundamento dos valores democráticos. E este debate se impõe seja para a PC Norte-americana, que vem se deparando com críticas e questionamentos acerca de seu aporte teóricoepistemológico, precisamente sua vertente cognitivista, seja para a PC Latino-americana que abraçou as principais correntes teórico-metodológicas do Marxismo na América Latina (Freitas, 1996) e hoje se depara com um mundo mais complexo do que a divisão de classes sociais tradicional e a exploração sobre as relações de trabalho.

Em nossa visão, as grandes diferenças entre uma e outra existem, precisamente nas opções teóricas e metodológicas e no desenvolvimento histórico, porém, ao abraçarem, respectivamente, posturas mais individualistas no hemisfério norte e posturas mais comunitaristas no hemisfério sul, tanto uma como a outra, apontam para o fim do político, logo, acenam com um comprometimento frágil na radicalização de valores democráticos plurais e multiculturais. Segundo Mouffe (1993), esta radicalidade pode ser pensada somente com a garantia da sobrevivência da tensão entre a lógica da identidade e a lógica da diferença:

“É esta tensão, de fato, que também aparece como a tensão entre nossas identidades como indivíduos e como cidadãos ou entre os princípios de liberdade e igualdade, que constituem a melhor garantia de que o projeto da democracia moderna está vivo e habitado pelo pluralismo. O desejo de resolver esta tensão poderá favorecer somente a eliminação do político e a destruição da democracia." (p. 133)

A Política e a Radicalização dos Valores Democráticos: As Novas Fronteiras do Político

A Política, como Bobbio, Matteucci e Pasquino (1993) referem-se, diz respeito "a tudo que se refere à cidade e, conseqüentemente, o que é urbano, civil, público, e até mesmo sociável e social" (p. 954). Neste sentido, o termo refere-se a tudo que, de uma ou outra forma, está relacionado às formas de poder reguladoras do agir social, isto é, a tudo que diz respeito ao social e as formas de poder de coação de uns sobre os outros.

Nas concepções mais modernas, a Política ocupa um lugar distinto, sobretudo porque a concepção de política foi sendo limitada, como mais uma vez, nos ilustram Bobbio e colaboradores (1993):

"Enquanto a filosofia política clássica se baseia no estudo da estrutura da pólis e das suas variadas formas históricas ou ideais, a filosofia política pós-clássica se caracteriza pela contínua busca de uma delimitação do que é político (o reino de César) do que não é político (quer seja o reino de Deus, quer seja o de Mammona), por uma contínua reflexão sobre o que distingue a esfera da Política da esfera da não-Política." (p. 960)

Assim, a política relaciona-se com as formas de poder de uns sobre os outros, formas estas que, segundo Bobbio e colaboradores (1993), podem ser ideológicas, políticas e econômicas. Mas as formas de poder político são as formas de poder às quais todos os demais estão de algum modo subordinados e, isto só faz-se verdadeiro, em uma sociedade de desiguais. 
"Conforme o que se disse até aqui sobre o significado restritivo de Política (restritivo em relação ao conceito mais amplo de 'social'), fim da Política significa exatamente fim de uma sociedade para cuja coesão seja indispensáveis as relações de poder político, isto é, relações de domínio fundadas, em última instância, no uso da força. Fim da Política não significa, bem entendido, fim de toda a forma de organização social. Significa, pura e simplesmente, fim daquela forma de organização social que se rege pelo uso exclusivo do poder coativo."(Bobbio, 1993, p. 960)

Através desta concepção, podemos sublinhar algumas questões fundamentais para a compreensão do político enquanto campo de publicização de conflitos. Iniciaremos pela idéia desenvolvida por Bobbio e colaboradores de que, no campo da política, a questão dos conflitos está sempre presente. O conflito e as formas de coação caracterizam o campo de disputa política. Não por outro motivo, o poder político está baseado sobre diferentes formas de forças que buscam manter a subordinação de uns aos outros. Para além destas características, temos um outro fator importante nesta visão, o de que a esfera do público é a esfera onde os conflitos são expressados. Ao abraçar esta idéia, estamos compreendendo que a esfera pública é a esfera da explicitação de subordinações (sejam elas relativas ao campo do doméstico, da intimidade ou da coletividade). Relações de subordinação, que na concepção de Mouffe (1988), ao se transformarem em discursos antagônicos no público tornam-se relações de opressão, pois é lá que podem ser tematizadas como relações de poder historicamente fundadas e recriadas ${ }^{4}$.

Estas questões, se nos ajudam a desenhar uma compreensão do político, também nos fornecem uma compreensão homogênea do campo. Para tomar alguma diferenciação, vamos buscar explicitar e especificar, ainda mais, uma compreensão do político que, como salientamos na abertura deste trabalho, nos ajude a compreender os discursos científicos da Psicologia Comunitária nas Américas.

Mouffe (1993, 1995, 1996, 1999) tem desenvolvido uma concepção do político que está, criticamente, baseada na abordagem amigo/inimigo de Carl Schmitt. A autora tem se preocupado com uma concepção que não

${ }^{4}$ A este movimento se dá no nome de princípio de equivalência. Como explicita Barret (1994): "Assim nasceu a lógica da equivalência: passamos de uma ordem social em que os sujeitos estavam posicionados de manoira diferencial, porém imutável, para uma ordem social em que o projeto democrático pode articular-se num discurso político que considero esses posicionatos diferenciados como objeto de luta. Portanto, a revolucas pamocrática promove uma ló

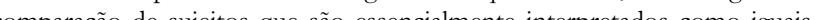
comparação de sujeitos que são essencialmente interpretados como iguais,

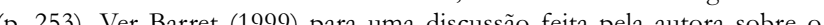
(p. 253). Ve Barte (19) para uma discussão féra pela ansora sobre o

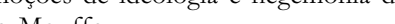

Psicologia: Reflexão e Crítica, 2002, 15(1), pp. 201-210 mantenha nenhuma essencialidade e que represente a pluralidade e a diversidade das relações antagônicas nas sociedades modernas e, para tal, considera que devemos pensar uma concepção com e contra Schmitt, no sentido de que, através de uma visão crítica à abordagem amigo/ inimigo de Schmitt, segundo Mouffe (1999), poderíamos construir uma concepção que, ao menos, não elimine os conflitos relativos às relações de opressão e a pluralidade característica do projeto moderno de democracia. Desta forma, a autora busca retomar as críticas de Schmitt ao pensamento liberal porém, refuta o que em Schmitt parece ser, de fato, a principal hostilidade entre os grupos sociais, a qual não tem limites para sua expressão. Assim, Mouffe (1999) precisa que, pensar com Schmitt também é pensar contra ele, já que, para a filósofa, a relação amigo/inimigo, em sua denominação amigo/adversário, estaria sempre limitada pelos valores da liberdade e da igualdade.

A posição de Schmitt tem sido refutada por muitos teóricos, como é o caso de Heller (1991) ao apontar para o discurso exclusivista que as concepções da Filosofia Política têm passado, seja de Schmitt a Arendt e de Luckács a Heidegger. Segundo Heller, há sempre a expulsão de alguém ou de algo nestas concepções, o que revela o que a autora húngara chamou de "obsessão pela exclusão" como uma das características da Filosofia Política radical. De fato, Heller aponta para algo valioso, pois se o político exclui sempre alguém ou algo, seja este algo uma variedade de temas e discursos, poderíamos supor que o político se assemelhe, em seu grau máximo, à hostilidade.

Porém, é com Mouffe, em sua releitura de Schmitt, através da concepção amigo/adversário, a qual coloca a relação antagônica como fundante da natureza do político, que podemos aprofundar estas questões, pois a autora não abraça de maneira incondicional a postura de Schmitt, pelo contrário, propõe, como já dissemos, pensar com e contra ele. De maneira que o político, para a autora, pode ser pensado como um espaço onde conflitos e antagonismos buscam realizar-se, tendo como conseqüência a impossibilidade do consenso e, neste sentido, Mouffe se alinha à Schmitt, considerando que o político "é uma contraditória combinação de princípios irreconciliáveis"(1993, p. 133). Porém, ao se alinhar, ela o redimensiona enfatizando dois aspectos que são fundamentais para a compreensão desta expansão das fronteiras do político, onde sempre há a exclusão: a lógica da identidade e a lógica da diferença, que buscam construir suturas uma à outra.

Para Mouffe (1993), a expansão do político sobre esferas da vida social é a possibilidade de radicalização da democracia, dada tanto pelo reconhecimento do princípio de equivalência, portanto do reconhecimento 
da igualdade entre os grupos sociais, como do princípio da diferença, ou seja, o reconhecimento de que particularidades podem revelar formas múltiplas de opressões.

Esta concepção de político recoloca uma especificidade desta esfera fundamental: a fronteira política, a qual permite que uma relação de subordinação seja reconhecida como historicamente determinada, portanto, que seja vivida como opressão e não mais como naturalização da vida social, já que agora, no político, pode ser reivindicado o direito à equivalência, portanto, ao fim das relações de opressão. Neste sentido, o campo do político configurase pela relação entre um coletivo que se constitui como um NÓS (identidade coletiva) versus um ELES (exteriorização da identidade coletiva). Importante ressaltar que, é a radicalidade dos princípios de liberdade e igualdade, típicos do discurso da democracia, que pode nos ajudar a pensar na relação NÓS versus ELES como relações baseadas na lógica da equivalência e da diferença. Estas relações (antagônicas) para colocarem-se como antagonismos políticos, devem ser entendidas a partir não somente da reivindicação pela equivalência, mas sobretudo pela reivindicação da diferença, já que, desta forma, a tentativa de se instalar um discurso sobre a identidade-NÓS é dada pela possibilidade do reconhecimento do discurso da identidade-ELES, como um constitutivo externo ao próprio NÓS. A possibilidade deste coletivo NÓS está sustentad na diferenciação de um ELES, ou seja, na esfera do político, o consenso é tão precário quanto a relação de exclusão, em outras palavras, o consenso está sempre sendo dado sob algum nível de exclusão, formando-se assim enquanto um consentimento possível, o que implica em um processo articulatório.

Pensar nestes termos é, em verdade, reconhecer o caráter antagônico do político, mas não necessariamente este caráter se dá pela contradição ${ }^{5}$. A diferenciação entre antagonismo e contradição, tarefa nada fácil, sempre tem sido uma disputa teórica e analítica entre diversos autores marxistas. Segundo Bottomore (1988), as contradições em Marx são contradições dialéticas porque, se opondo tanto as oposições das lógicas formais e às oposições das lógicas exclusivas, as contradições, " marca registrad de toda a dialética ontológica marxista", "constituem oposições inclusivas reais, pois seu termos pressupõem existencialmente seu oposto e porque são sistemática ou internamente relacionadas com uma forma de aparência mistificadora" (p. 80). Assim, na contradição marxist está incluído um elemento interno a dialética - oposição inclusiva - de maneira que esse elemento é a condição

${ }^{5}$ Ver para esta reflexão pormenorizada Laclau (1990). para sua superação. A dialética e o seu elemento interno predeterminam o elemento subseqüente, e no antagonismo não está dada uma conexão interna que possa predeterminar o elemento subseqüente. Neste sentido, configurar-se como um discurso antagônico não determina sua abrangência, nem tampouco sua solução. Sua abrangência estará determinada pelo processo de constituição das identidades coletivas e dependerá, em muito, das possibilidades de articulação, dos contextos históricos em que estão inseridas e dos processos de demarcação de fronteiras (Howarth \& Stravrakakis, 2000; Laclau, 1990).

A relação antagônica não apresenta como sua possibilidade final o consenso, pois como este somente poderá se dar ao excluir um ELES da concepção do NÓS, o antagonismo é permanente, alimentando desta maneira uma tensão necessária para o espaço democrático e, evitando assim um sujeito coletivo totalizado e fechado sobre si mesmo e um constitutivo externo como impossibilitado de constituir-se como um possível NÓS. A idéia central ao apontar para as fronteiras do político, é poder entender que a possibilidade da comunidade política está no seu sempre constitutivo externo e, este como possibilidade, também é a impossibilidade do fechamento desta comunidade sobre si mesmo.

A negação destas fronteiras seria, para a autora, um dos maiores perigos para o aprofundamento dos valores democráticos, já que, negá-las seria afiliar-se a um tipo de democracia - a liberal - na qual a ilusão do consenso razoável e racional parece não excluir ninguém, mas como temos visto, exclui tão somente pela noção de racionalidade política . "A exclusão do diferente portanto é baseada na lógica do exercício livre da prática da razão"(Mouffe, 1993, p. 142). Ou também, por outro lado, seria abraçar um NOS que, sem a fronteira, ou seja, indiferenciado de um ELES, corre o risco de negar as práticas plurais e reduzir as múltiplas formas de luta democrática, sejam as de gênero, de raça, sexual, ecológica, de classe e outras, a uma definição de "vida decente" única, baseada em valores morais, definido por grupos estratégicos.

Tentando escapar destas duas posturas essencialistas que impedem a composição do político como espaço de articulação das identificações NÓS-ELES, poderíamos supor, então, o comunitário - portanto, o NOS - como uma tentativa de antagonização com um ELES, e este conflito não poderia conciliar-se como um consenso razoável ou mesmo como uma política de redenção, que se coloca muito mais como funcional do que ontológica. Nesta medida, o comunitário não correria o risco de totalizar-se, dadas as contingências articulatórias em 
sociedades cada dia mais complexas. A comunidade poderia ser como mais uma das formas de identificação possível dos sujeitos, mas não aquela que impede a pluralidade de outras formas ao definir o consenso sobre a liberdade individual.

"É vital reconhecer que, para a construção de um NÓS é necessário distinguí-lo de um ELES e que todas as formas de consenso estão baseadas em atos de exclusão, a condição de possibilidade de uma comunidade política é ao mesmo tempo a condição de impossibilidade de sua inteira realização." (Mouffe, 1995, p. 36)

Porém assumir esta posição seria rever tanto as posturas individualistas na Psicologia Comunitária da América do Norte, como a comunitaristas na Psicologia Comunitária da América Latina e, para isto, sem dúvida, deveríamos ir além destas polaridades que parecem não deixar espaço para compreender a constituição das comunidades políticas. Mas, antes de avançarmos para esta terceira posição, temos que reconhecer e compreender como estas duas posições da PC nas Américas podem se tornar uma espécie de postura anti-politico.

\section{Psicologia Comunitária na América do Norte}

A PC nos EUA surgiu como um movimento alternativo ao pensamento psicológico dominante até os anos 60 de explicação das ações humanas no mundo social. Ela foi marcada pelo descontentamento de uma parte de psicólogos com a insuficiência teórica que, até então, a Psicologia estava submetida, especialmente na relação com a Medicina e a Psiquiatria. A preocupação com estudos que enfrentassem uma compreensão da ação humana frente aos conflitos sociais foi, de início, a pretensão deste movimento científico-político chamado Psicologia Comunitária (Klein, 1987).

Os psicólogos, segundo Rickel (1987), foram encorajados a serem participantes ativos dos problemas da sociedade e, portanto, foram chamados a tornaremse agentes de mudanças. Na reflexão de Sarason (1984), este movimento implicou em rever o modelo psiquiátrico e clínico para o tratamento de questões relacionadas à saúde mental. Segundo o autor, o desejo de um novo setting profissional estava na lista de reivindicações dos grupos articuladores desta nova postura na Psicologia, que nada mais eram do que grupos de psicólogos clínicos que alertavam para o fomento de um novo campo profissional que já nascia reivindicando diferenças da medicina e das visões mais clinicalistas. Sarason (1984) aponta para quatro questões relevantes que marcaram o surgimento do movimento da PCNA, em suas palavras:

"Foi uma revolta de longa turbulência contra a dominação

psiquiátrica junto aos profissionais da saúde mental. Em termos de valor profissional, de orientação teórica, de pesquisa e de lugares de prática, os psicólogos clínicos se sentiam limitados e desperdiçados” (Sarason, 1984, p. 201);

"Havia uma consciência crescente de que, para uma grande parte da população, os serviços de saúde não existiam, ou se existiam, estavam muito além das possibilidades financeiras desta população ou inapropriados em seu aspecto cultural. Não somente os serviços de saúde tinham uma distribuição desigual na sociedade, mas também as profissões de saúde mental eram dependentes de visões estreitas de tratamento que não eram sensíveis às variações culturais e raciais" (Sarason, 1984, p. 201);

"Estes psicólogos clínicos, conscientes das forças que estavam promovendo destrutivos conflitos comunitários e polarizações, no início dos anos 60 , reconheceram que tinham que entender a natureza destas forças e procurar caminhos que as influenciassem. A Psicologia Clínica tradicional tinha pouco ou nada a contribuir com tal entendimento ou intervenção" (Sarason, 1984, p. 201);

"A psicologia clínica se preocupa com o comportamento e os eventos depois que eles se tornavam problemáticos. Deixando esta questão de lado, psicólogos clínicos começaram a ver os limites do approach clínico: o fracasso ou a inabilidade para pensar em termos de prevenção.” (Sarason, 1984, p. 201) Nos termos deste teórico, as questões sociais e, porque não dizer políticas, relacionadas à distribuição do poder junto aos grupos sociais, passavam a ser postas como problemas para a Psicologia. Portanto, vemos que este movimento Norte-americano pretendia uma nova interpretação da Psicologia que, mesmo que não fosse uma interpretação axiomática, era uma aproximação da ciência do indivíduo ao mundo do político.

A PCNA se estabelece, assim, como um campo derivado da Psicologia Clínica naquele país, que sempre esteve atrelada a noções de mudanças comportamentais e individuais. A PCNA, que parecia estar disposta a rever a Psicologia no seu estatuto mais individualizante, na verdade confirma-se enquanto uma Psicologia que amplia a idéia de clínica, materializando o indivíduo como supremacia de qualquer entendimento sobre o mundo social, as relações de poder e as ações grupais.

Ilustrativa desta questão é a referência de Manicas \& Secord (1983), ao apontarem o reducionismo psicológico da psicologia social nos EUA:

"a prática mais popular dos psicólogos sociais, para os quais a disciplina é a Psicologia, tem sido retirar os indivíduos de seus mundos sociais e estudá-los em um relativo isolamento. Considerando muitos dos temas dominantes nas pesquisas, tanto no passado como no presente, vemos: atitudes e mudanças de atitudes, defesa perceptiva, a percepção de pessoa, teoria da consistência cognitiva, teoria da dissonância, teoria da igualdade e, presentemente, a teoria da atribuição. Em todos estes, o foco é usualmente um olhar 
para dentro dos processos cognitivos mais que para fora nas situações e estruturas sociais". (pp. 408-409)

A PCNA, então, relaciona-se, tanto com o processo que Manicas e Secord (1983) denominaram de americanização das ciências sociais, como com o que Farr (1996) intitulou de individualização da psicologia social para expressar o movimento que mesmo ao buscar relacionar o indivíduo e o mundo social, acaba por reduzir esta relação a um dos extremos. A $\mathrm{PC}$, neste continente, não pode ser vista como um bloco totalmente homogêneo ${ }^{6}$, mas poderíamos dizer que ela tem se caracterizado por uma abordagem do político na qual a supremacia é do indivíduo

Isso pode ser visto, quando retomamos os estudos sobre o empowerment, desenvolvidos pelos psicólogos comunitários Norte-americanos. O conceito de empowerment tem significado uma tentativa desta Psicologia em buscar os nexos entre o indivíduo e seu contexto (Perkins, 1995). Como em outras posições, esta perspectiva, a do empowerment, argumenta a favor da importância do contexto social para formação do pensamento e do comportamento humano. Mas vamos, antes, esclarecer ao leitor o que significa o termo empowerment na PCNA.

Empowerment seria um processo através do qual as pessoas, organizações e comunidades tornam-se conscientes proprietárias de suas próprias vidas, isto a partir tanto do controle pessoal, como da influência social. Rappaport (1981, 1987) sugere que este processo se dá, tanto por uma determinação individual da autonomia com a própria vida como por uma participação democrática na vida da comunidade. Neste sentido, articulado como um conceito capaz de uma compreensão da relação do indivíduo com o mundo social, o empowverment define como níveis de atuação e entendimento, os níveis individual, grupal e comunitário (Zimmerman, Israel, Schulz \& Checkoway, 1992). Porém, pensado à luz de uma concepção liberal de participação, o empowerment tem se tornado um elemento de compreensão do que acontece "dentro da cabeça dos indivíduos" (Riger 1993 , p. 282). Nesta lógica, tem buscado explicar a autonomia individual, como fomentá-la no sentido de colaborar para que os sujeitos possam influenciar os seus contextos e os seus ambientes; nas palavras de Riger "Muitas intervenções têm sido objetivadas através do empowerment, como por exemplo, o aumento do poder

Gostaríamos de destacar que, neste texto, apontamos para uma vertente mais dominante da PC nos Estados Unidos da América, que se caracteriza pelo estudo do empowerment de base sócio-cognitivista, porém, não podemo tomar esta como sendo a postura unânime das posições teóricas naquele país e, particularmente na PC é importante ainda dizer que teóricos como Newbrough (1980) tem buscado estabelecer um diálogo com a filosofia e impresso uma marca mais histórica para as análises da PC naquele continente. de ação das pessoas por realçar sua auto-estima, mas fazem pouco por apontar o poder delas sobre os recursos e as políticas" (p. 282). O que pode ser compreendido como uma interpretação ideologizada, já que a questão do poder, como vimos com Bobbio e colaboradores (1993), coloca-se no campo de disputas em diferentes níveis, não somente no nível individual.

Stephanie Riger (1993) vai mais longe ao desenvolver estudo sobre o conceito e o uso do empowerment na PC Norte-americana, diz a autora:

"História e cultura moldam os conceitos que nós usamos para explicar a ação humana. Talvez o mais importante valor formador da Psicologia seja a crença no individualismo, uma crença que repousa no coração da visão de natureza humana da Psicologia. Uma grande parte das pesquisas, nesta ciência, é baseada na idéia de que o indivíduo saudável é aquele que é auto-contido, independente e dependente de si mesmo, capaz de afirmar-se, influenciar seu ambiente e operar de acordo com princípios abstratos de justiça e igualdade.” (p. 280).

Vê-se que, não somente materializado em uma perspectiva valorativo-social, mas também técnicocientífico, o modelo do empowerment, seguindo a tradição cognitivista, coloca-se como uma forma de sóciocognitivismo que tem como resultado a focalização na percepção individual e uma desconexão desta com o contexto sócio-político, como afirma Riger (1993),

“a conseqüência de uma perspectiva cognitivista é ignorar ou minimizar a influência dos fatores situacionais ou sócioestruturais em favor de um focus na percepção individual. Mas esta visão, artificialmente desconecta o comportamento humano do contexto sócio-político como um todo, resultando em uma busca, dentro do self, para soluções aos problemas humanos (...). Neste contexto, se o focus de questionamento torna-se não o poder atual, mas, pelo contrário, a percepção do empowerment, então, o político é formado pelo pessoal e, ironicamente, o status quo pode ser mantido."(p. 281)

Nesta compreensão da PCNA temos uma visão liberal do político, primeiro porque o poder está reduzido a capacidade mental e de ação de um indivíduo -"ignora o contexto político e histórico nos quais as pessoas operam" (Riger, 1993, p. 282) - e, segundo, porque se reduz o sujeito político, este sujeito capaz de tematizar conflitos sociais, a capacidade racional e mental de controlar o mundo ao seu redor, como se sujeito e político estivessem conectados, além de artificialmente, racionalmente.

O político, nesta visão, propicia uma participação política, via de regra institucionalizada, de controle sobre 
ações institucionais e/ou de grupos ${ }^{7}$. O que vale ressaltar, neste caso, é o que foi discutido por Mouffe (1993), que o político, na visão liberal, reduz-se a uma participação racional, como em um mercado de interesses e negociações. O que se retira do político é o processo de constituição dos antagonismos sociais, ou seja, a capacidade de grupos e coletivos constituir-se em sujeitos coletivos na configuração de uma arena pública, onde, se debatem e tematizam questões que, pouco a pouco, vão sendo politizadas.

O pensamento liberal, segundo Mouffe (1993), baseado em uma liberalização da ética para o campo da troca de interesses e lobbies, traduz o político como o mundo institucional e racional que se subordina ao mercado e sua lógica. O sujeito racional, não por acaso, atende a um modelo de organização civil, própria de um grupo social. O modelo de racionalidade, neste projeto, permite considerar que o político pode ser constituído abstraindo e/ou remetendo para o mundo privado, todas as paixões e emoções humanas.

Reconhecer que a PCNA tem tratado, em alguns casos, o político enquanto um tribunal de barganhas, é reconhecer sua institucionalização enquanto prática. Parece que o conflito só é reconhecido, nesta visão, enquanto um conflito com traços de uma racionalidade tipicamente liberal e uma institucionalização promovida pela idéia de que ordenar é o melhor remédio. $\mathrm{O}$ aspecto normativo do político é tomado, segundo Piven e Cloward (1992), como algo tautológico, excluindo-se o reconhecimento das relações de opressão e de submissão de uns aos outros. Os discursos que não se colocam como racionais neste modelo de intervenção da PC, são relegados à erupção do irracional e do pouco organizado discurso institucional. É óbvio neste modelo que, a definição do político como um sistema moral que propõe a institucionalização e a lei como lugar de tematização da vida em sociedade, produz um tecnicismo da prática política (os lobbies), com o objetivo de criar a ilusão de um consenso na lei. A idéia substantiva que, através deste modelo, se tenta materializar é que a lei e a justiça são a mesma coisa. Logo, o político não poderia ser tão diferente do que se caracterizam as trocas de interesses, mesmo que reguladas por alguns princípios éticos, como tem sido o caso das propostas dos liberais ontológicos, que remetem todas as diferenças humanas ao mundo privado.

"Todas as questões controversas estão fora da agenda (dos liberais) na tentativa de criar as condições para um

Para esta afirmação ver as temáticas que têm sido trabalhadas pela PC Norte-americana, no American Journal of Community Psychology. Ou consultar Speer e colaboradores (1992). consenso racional. Como resultado, o campo da política torna-se meramente o terreno onde indivíduos, desvestidos de suas paixões e crenças, que rompem a ordem, e entendidos como agentes racionais na busca de vantagens próprias - dentro das coesões morais, é lógico - submetem-se aos métodos de advogar entre suas reivindicações, as quais eles consideram justas. Esta é uma concepção de político na qual reconhece-se prontamente um caso típico de negação liberal do político." (Mouffe, 1993, p. 140)

A partir da conceituação do empowerment, podemos compreender que a PCNA propõe, ao afirmar o trabalho de potencializar a capacidade dos indivíduos e grupos de "ter controle" sobre suas vidas, o fim do político. A morte do político, assim, não permite à Psicologia estudar o que deveria ser princípio de uma sociedade democrática: o surgimento de novos sujeitos políticos pois eles emergem e se constituem enquanto tais, a partir do reconhecimento de novas formas de opressão. Eles, de acordo com seu tempo histórico, surgem e organizam-se em identidades coletivas, criando assim processos articulatórios que, sem dúvida, poderiam interessar em muito a uma Psicologia Comunitária compromissada com a participação social dos sujeitos (Prado, 1999).

\section{A Psicologia Comunitária na América Latina}

Contra esta noção de um sujeito utilitarista travestido de social - na expressão de Glória Gohn (1997) - o pensamento político organizado em torno da noção de bem comum, a partir dos identificados como comunitaristas, foi extremamente importante, pois não deixou o político e as concepções sobre participação nas mãos do utilitarismo liberal, apontando, assim, para uma das noções sobre sujeito político mais importantes para o pensamento social, "a de que o campo do político é onde nós podemos reconhecer a nós mesmos como participantes de uma política comunitária" (Mouffe, 1993, p. 61). E é neste contexto, que podemos refletir sobre a PCLA.

A PCLA possui uma história bastante distinta de sua irmã Norte-americana, sobretudo porque ela incorporou características históricas, sociais e políticas dos países mais pobres, que passaram por ditaduras militares e que tiveram uma organização dos partidos de esquerda bastante distinta da organização Norte-americana (Montero, 1994; Wiesenfeld, 1994; Wiesenfeld \& Sanchez, 1994). Se lá a PC estava mais vinculada ao movimento de saúde comunitária, aqui ela estava, enfaticamente, sendo proposta como uma atividade política. As influências tanto da Teologia da Libertação e das práticas das Comunidades Eclesiais de Base (CEBs), como dos estudos de Paulo Freire (Freitas, 1996), são evidentes na construção desta postura da Psicologia Comunitária. Além 
disso, não podemos relegar ao esquecimento que a PC na América Latina iniciou suas práticas no momento em que muitos dos países latinos viviam ditaduras militares, e que, para muitos psicólogos, a PC, naquele momento, significava um espaço relativamente seguro de militância política. Estas influências deram à PCLA um caráter muito menos individualista e mais politizado do que a PC Norte-americana ${ }^{8}$.

A PCLA nasceu, ao nosso ver, como uma importante reação à colonização do pensamento liberal na Psicologia seja no campo do político, ou mesmo nos processos de legitimação científica. As preocupações sociais e a negação de um sujeito individualizante foram axiomas importantes para a fundação da PC na América Latina (Andery, 1984). Assim, ela tem sido um locus de reflexões sobre a própria Psicologia enquanto ciência e seus compromissos com uma sociedade mais democrática. Porém, ao abraçar a idéia de bem comum substancializado (Prado, 1999), esta PC, ao menos no que diz respeito ao campo do político, tem se aproximado da PC Norte-americana. Mas vamos, passo a passo, aproximar-nos desta idéia.

Intencionada pela afirmação do bem comum como um definidor do sujeito, a PCLA tem vivido o dilema de refletir sobre uma possível relação entre indivíduo comunidade. Ela tem encampado a idéia comunitarista de que valores morais compartilhados definem participação democrática. De maneira que estaríamos sendo cada vez mais sujeitos políticos e conscientes quanto mais vida comunitária e quanto mais compartilhássemos valores morais definidos pela idéia de bem comum como guia da vida social e individual.

Na PCLA, o ideal do coletivo - a comunidade - é visto como um conjunto de atividades, discursos e práticas capaz de criar autenticidade identitária (a identidade verdadeiramente humana). Não por outro motivo, vemos, em muitos dos trabalhos de intervenção comunitária, uma noção de comunidade sendo trilhada como ideal de vida comum, de consenso, que nega, totalmente, a idéia de antagonização social enquanto um processo político, pois, nesta noção o antagonismo é somente funcional e temporariamente admitido até que se possa construir um conjunto normativo de definição da identidade coletiva, que muitas vezes se apresenta como uma negação total da sociedade, já que esta é desumana e ideologizada.

O político, nesta idéia, é sensivelmente negado, pois se a comunidade pode alcançar o lugar do consenso

${ }^{8}$ Para um acompanhamento mais detalhado tanto da história como das práticas desta psicologia comunitária, consultar Freitas (1996). humanizado, libertador e de relações face-a-face, ela se contrapõe totalmente a seu inimigo: a sociedade capitalista, nesta visão, impeditiva da autenticidade identitária, logo, o político reduz-se a uma etapa da construção da transparência social.

A ilusão de um consenso comunitário, sustentado pelas noções de identidade autêntica e de consciência transitiva crítica (Góis, 1984, 1994 referindo-se aos trabalhos de Freire, 1979 e Cavalcante, 1989), aprimora-se ao propor que é possível o desenvolvimento de uma comunidade ou de relações comunitárias como inclusão, sem evidenciar então, que qualquer processo de criação de um consenso implica necessariamente um processo de exclusão, e é, segundo Mouffe (1993), esta relação entre a afirmação da igualdade e da diferença que garante que a inclusão não se transforme em uma totalização da vida do sujeito e, ao mesmo tempo, garante a radicalização e a sobrevivência do político como o lugar de radicalização dos princípios democráticos.

Esta ilusão da conciliação pela redenção do político, dá-se na aniquilação do espaço do político como espaço de conflito que não se reduz a uma posição identitária, pois tem sido entendido, nestas perspectivas comunitárias mais essencialistas, que o fim dos antagonismos seria responsável pelo alcance da identidade autêntica do EU, como afirma Zizek (1990):

"Baseia-se precisamente no fato de que o 'capitalista', este inimigo externo, é quem está me impedindo de alcançar uma identidade comigo mesmo: a ilusão é que depois da eventual aniquilação do inimigo antagonístico, EU poderia finalmente abolir o antagonismo e alcançar uma identidade para o meu EU.” (p. 251)

A perspectiva de que este EU/NÓS possa trazer a transparência social e de si mesmo, tornou-se um projeto tão tautológico quanto outro qualquer na PC Latinoamericana, e por este motivo, esta Psicologia corre o risco, nos dias de hoje, de abandonar seu mais importante prefácio: o de politizar a vida psicológica.

Esta Psicologia nasceu como importante reação ao pensamento liberal (Prado, 1997), como já notamos, porém, ela abraçou, com alguma rapidez, um ideário tão essencializado quanto o que pretendia criticar, fazendo, por sentido inverso, uma negação do espaço do político tal qual o pensamento liberal vinha e vem, cada dia mais forte, desenvolvendo

A PC Latino-americana ao declarar seu sentido de que tudo é político, sem perceber, neutraliza a possibilidade do político existir, pois se tudo se transforma em político, não há uma publicização nem das formas aliadas, nem adversárias em um campo específico de tematização das 
relações de opressão. Assumir o político enquanto tal, é estar implicado na idéia de que nada, nenhum grupo social, nem nenhuma identidade política, pode ser vista como portadora de qualquer autenticidade, não sendo possível então, a construção de uma identidade comunitária capaz de abarcar a transparência do real, onde, por ilusão, não existiria mais consciências semi-transitivas.

Temos visto então que o político estaria liqüidado em uma concepção, tanto liberal como comunitária de participação social, de forma que, a oposição entre as duas lógicas de pensamento informam-nos, pela negatividade que as contém, uma lógica muito parecida: a da exclusão do político.

\section{Psicologia Comunitária e o Político: Em torno de} uma Psicologia Política

Mouffe (1993) argumenta que para rever estas posições deveríamos abandonar, logo de começo, qualquer princípio que mantenha a noção de um coletivo político preso, tanto ao status da lei - um agregado de interesses individuais como nos quer fazer crer o pensamento liberal -, como preso unicamente a noção de bem comum, de forma que deveríamos manter em campos separados a moralidade e a política, o que não significa, em hipótese alguma, retirar qualquer princípio ético do campo político, mas sim, subtrair qualquer idéia substantiva de bem comum como valores compartilhados que devem determinar e unificar as posições dos sujeitos políticos.

Ao manter o substancialismo destas duas posições nas duas Américas - a PC, seja acima da linha do Equador ou abaixo, mantém a mesma lógica intrínseca: negação do pluralismo e o fim do político. A (des)substancialização do político, seja como consenso racional ou como valor moral compartilhado, abriria um campo fundamental de estudos sobre a articulação e a constituição de discursos e práticas sociais coletivas que formam, ou buscam formar, sujeitos coletivos. O apelo a uma idealização da "identidade comunitária", como vem sendo proposto pela PC Latino-americana, impede-nos de compreender o processo, pois coloca, no patamar epistemológico, um essencialismo identitário. Smith afirma que esta postura

"ignora o papel constitutivo de mediação do discurso político e destina para o indivíduo um interesse autêntico que é suposto diretamente da sua posição estrutural (no caso da PCLA, esta suposição, ou até pressuposto, tem estado presente na idéia de alienação, necessidades radicais, pobreza e etc...). Pressupõe-se que trabalhadores, portanto não proprietários, tenham um interesse autêntico nas lutas socialistas contra o capitalismo, tal como se pressupõe que as mulheres em sociedades sexistas tenham um interesse autêntico nas lutas feministas, e assim por diante. Onde indivíduos não atuem em concordância com seus interesses autênticos - onde trabalhadores votem por propostas conservadoras, mulheres rejeitem o feminismo, minorias raciais se oponham a ação afirmativa e assim por diante $3 / 40$ diagnóstico essencialista é que eles estão sob a falsa consciência e requerem firmes lideranças para guiá-los em direção a seus autênticos interesses.” (p. 58)

É compreendendo as mediações destes discursos que a Psicologia Comunitária pode entender a composição das identidades comunitárias e políticas. Ao nosso ver, isto significa reconhecer que a exclusão é um constitutivo presente em todas as formas de constituição de um NÓS, já que esta seria a maneira de distinção entre “(...) as diferenças que existem mas não deveriam existir e as diferenças que não existem mas deveriam existir." (Mouffe, 1995, p. 36)

Pensamos ser este um caminho gerador de um importante debate, e nossas reflexões buscam somente participar dele. Refletir sobre estas práticas e investigações talvez nos faça assumir, como tarefa científica, o político enquanto um campo de trabalho, dado, desta forma, por estudar e entender as pré-condições (sejam elas materiais, simbólicas, institucionais, psicossociais, éticas ou políticas) que são necessárias para a constituição de uma participação comunitária enquanto mais uma possibilidade, entre as múltiplas existentes, de construção de discursos antagônicos (Prado, 1999). Neste sentido, a PC deve ser encarada como mais uma prática que, dentre outras, poderia colaborar para a compreensão dos processos articulatórios na constituição de um coletivo não substancializado pela idéia de vida boa, mas acima de tudo, enquanto uma identificação política que temporariamente expressa a sutura de uma posição identitária dos sujeitos, mas que enquanto identificação não se reduz a uma identidade préconcebida, já que está determinada pelos seus adversários.

Este processo articulatório pode ser nosso objeto de interpelação, pois é nele que iremos encontrar os elementos que constituem as identidades e os discursos dos sujeitos, através dele que poderemos entender o porquê, muitos grupos populacionais pobres na América Latina não constituem, ainda, um espaço de politização das inúmeras subordinações que os desumanizam. E este processo não é psicológico, mas sobretudo, psico-político, já que revela uma política de identidade sobre a definição de mundo e de sujeito, assumindo desde o começo que, esta formação identitária coletiva é expressa como a formação de relações de poder.

\section{Referências}

Andery, A. (1984). Psicologia na comunidade. Em S. Lane \& W. Codo. (Orgs.) Psicologia social: O homem em movimento (pp. 203-220). São Paulo: Brasiliense. 
Barret M. (1999). Ideologia política e hegemonia: de Gramsci a Laclau e Mouffe. Em Zizek, S. (Org.), Um mapa da ideologia (pp. 235-264). Rio de Janeiro: Contraponto

Bobbio, N., Matteucci, N. \& Pasquino, G. (1993). Dicionário de politica. Brasilia: Editora da Universidade de Braślia.

Bottomore, T. (Org.). (1988). Dicionário do pensamento marxista. Rio de Janeiro Jorge Zahar.

Farr, R. (1996). The roots of modern social psychology. Cambridge: Blackwell.

Freitas, M. F. Q. (1996). Contribuições da psicologia social e psicologia política ao desenvolvimento da psicologia social comunitária. Psicologic \& Sociedade, $8(1), 63-82$

Gohn, M. G. (1997). Teorias dos movimentos sociais: Paradigmas classico e contemporaneos. São Paulo: Loyol.

Goís, C. W. L. (1984). Proposta de um caminho para a psicologia junto classe oprimida: Por uma psicologia popular. Revista de Psicologia, 2(1), 87-122.

Góis, C. W. L. (1994). Noções de psicologia comunitária. Fortaleza: Edições UFC Heller, A. (1991). The concept of the political revisited. Em D. Hel (Org.), Political theory today (pp. 330-343). Stanford: Stanford University Press.

Heller, A. (1999). Uma crise global da civilização: Os desafios futuros. Em A. Heller. (Orgs), A crise dos paradigmas em ciências sociais e os desafios para o século XXI (pp. 13-32). Rio de Janeiro: Contraponto.

Howarth, D. \& Starrakakis, Y (2000). Introducing discourse theory and theory and political analysis: Identities, hegemonies and social change. (pp. 1-23). theory and political anaysis: Identities, hegemonits

Kelly, J. (1990). Changing contexts and the field of community psychology American Journal of Community Psycbology. 18(6), 769-791.

Klein, D. (1987). The Context and times at Swampscott: My/story. Americ Journal of Community Psychology, 15(5), 531-537.

Lane, S. (1995). Avanços da psicologia social na América Latina. Em S. Lan \& B. Sawaia (Orgs.), Novas veredas da psicologia social (pp. 67-82). São Paulo: Educ \& Brasiliense.

Linney, J. (1990). Community psychology into the 1990's: Capitalizing opportunity and promoting innovation. American Journal of Community Psychology, 18(1), 1-17.

Manicas, P. T. \& Secord, P. F. (1983). Implications for psychology of the new Philosophy of Science. American Psychologist, 38, 399-413. Montero, M. (1994). Vidas paralelas: Psicología comunitaria en latinoamérica
y en Estados Unidos. Em M. Montero (Org.), Psicologia social comunitaria y en Estados Unidos. Em M. Montero (Org.), Psicologita

(pp. 19-45). Guadalajara: Universidad de Guadalajara.
(19)

Mouffe, C. (1988). Hegemony and new political subjects: Toward a new and the interpretation of culture (pp. 89-102). Chicago: Univess
Press.

Mouffe, C. (1993). The return of the political. London: Verso.

Mouffe, C. (1995). Democratic citizenship and the political community. Em C. Mouffe (Org.), Dimensions of radical democracy: Phuralism, citizenshit, community. (pp. 225-239). London: Verso

Mouffe, C. (1996). Democracy, power, and the "Political". Em S. Benhabib (Org.) Democracy and difference: Contesting the boundaries of the political (pp. (Org.) Democracy and difference: Contesting the bounda
245-256). Princeton: Princeton University Press.

Mouffe, C. (1999) Carl Schmitt and the paradox of liberal democracy. Em C. Mouffe (Org.), The challenge of Carl Schmitt (pp. 38-53). Nova York: Verso

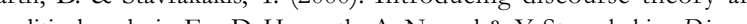

Laclau, E. (1990). New reflections of the revolution of our time. London: Verso. concept of democracy. Em C. Nelson \& L. Grossberg (Orgs), Marxism

Newbrough, J. R. (1995). Toward Community: A third position. American Journal of Community Psychology, 23(1), 9-37.

Novaco, R. \& Monahan, J. (1980). Research in community psychology: An analysis of work published in the first six years of the American Journal of Community Psychology. American Journal of Community Psychology, 8(2), 131-145.

Perkins, D. (1995). Speaking truth to power: Empowerment ideology as social intervention and policy. American Journal of Community Psychology, 23(5), 765-791.

Piven, F. \& Cloward, R. (1992). Normalizing collective protest. Em A. Morris \& C. Mueller (Orgs.), Frontiers in social movement theory (pp. 301325). New Haven: Yale University Press.

Prado, M. A M. (1994). A consciência e a constituicão de valores comunitários: Um estudo sobre os participantes de um mutirão habitacional na cidade de São Paulo. Dissertação de Mestrado não-publicada. Programa de Pós-Graduação em Psicologia Social. Pontifícia Universidade Católica de São Paulo, São Paulo, SP.

Prado, M. A. M. (1997). A psicologia e a utopia comunitária na transição do mundo moderno. Em M. Montero (Org.), Psicología y comunidad (pp. 48-58). Caracas: SIP \& UCV.

Prado, M. A. M. (1999). Problematizando o individualismo e o comunitarismo como posições identitárias [Resumo]. Em B. Sawaia, C. Alves \& O. Ardans (Orgs), Livro de Resumas, $10^{\circ}$ Encontro Nacional da Associasão Brasileira de Psicologia Social (p. 20). São Paulo: Abrapso.

Rappaport, J. (1981). In praise of paradox: A social policy of empowerment

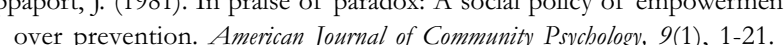

Rappaport, J. (1987). Terms of empowerment/exemplars of prevention: Toward a theory for community psychology. American Journal of Community Psychology, 5(2), 121-148.

Richel, A. (1987). The 1965 Swampscott conference and future topics for community psychology. American Journal of Community Psychology, 15(5), 511-513.

Riger, S. (1993). What's wrong with empowerment. American Journal of Community Psychology, 21(3), 279-292.

Santos, B. S. (1994). Pela mão de Alice: O social e o político na pós-modernidade. Porto: Afrontamento

Sarason, S. (1984). Community psychology and public policy: Missed oportunity: Americon Journal of Community Psychology. 12(2), 199-207.

Smith, A. M. (1998). Laclau and Mouffe: The radical democratic imaginary. Nova York: Routledge.

Speer, P., Dey, A., Griggs, P., Gibson, C., Lubin, B. \& Houghey, J. (1992). In search of community: An analysis of community psychology research from 1984-1988. American Journal of Community Psychology; 20(2), 195-209.

Touraine, A. (1995). Crítica da modernidade. Petrópolis, Rio de Janeiro: Vozes. Wiesenfeld, E. (1994). Paradigmas de la psicología social-comunitaria latinoamericana. Em M. Montero (Org.), Psicología social comunitaria (pp. 47-74). Guadalajara: Universidad de Guadalajara.

Wiesenfeld, E. \& Sanchez, E. (Orgs.) (1994). Psicologia social comunitaria: Contribuciones latinoamericanas. Caracas: Fondo Editorial Tropykos.

Zimmerman, M. Israel, A Schulz, A \& Checkoway, B. (1992). Further explo psychological empowerment. American Journal of Community Psychology, psychological $20(6), 707-727$

Zizek, S. (1990). Beyond discourse-analysis. Em E. Laclau (Org.), Nen reflection on the revolution of our time (pp. 249-260). London: Verso.

Recebido: 07/11/2000 Reservado: $17 / 07 / 2001$ Aceito: 06/08/2001

Sobre o auto

Marco Aurélio M. Prado é Professor do Mestrado em Psicologia da Universidade São Marcos (UNIMARCO), Doutor em Psicologia Social pela PUCSP, Membro da Diretoria Atual da Sociedade Brasileira de Psicologia Política. 